\title{
Comparison of Gender Equality in Children Education Policy and Classroom Between Norway and China
}

\author{
Fangjichen Tie ${ }^{1, *, \dagger}$, Hang Zhang ${ }^{2, *, \dagger}$, Shuhang Chen ${ }^{3, *,}$, Shuo Liang ${ }^{4, *, \dagger}$ \\ ${ }^{1}$ Dalian Minzu University, Dalian, Liaoning, China \\ ${ }^{2}$ University of Washington, Washington Seattle, United States \\ ${ }^{3}$ Beijing University of Technology, Beijing, China \\ ${ }^{4}$ University of Glasgow, Glasgow, Scotland, UK \\ *Corresponding author.Email: ${ }^{1} 1327671963 @ q q . c o m,{ }^{2}$ hangz4@uw.edu, ${ }^{3} 2998279419 @ q q . c o m$, \\ ${ }^{4} 773721726 @ q q . c o m$ \\ These authors contributed equally.
}

\begin{abstract}
Gender equality is a necessary condition for social justice and it is an important topic in the field of contemporary social sciences. Childhood is a critical period for shaping gender awareness. This article focuses on gender equality in children's education and compares the gender equality in children's education policies and classrooms in Norway and China. This study uses a quantitative research method to collect information on gender equality in Chinese children's education through questionnaires, and compares with the situation in Norway by combining education policies. Both countries have policies on providing gender equality programs dedicated to reducing discrimination and bullying. The difference is that China pays more attention to the balance of male and female teachers, while Norway has higher achievements in gender equality in pedagogy and sex education. In terms of classroom conditions, teachers in both countries encourage the communication and interaction between male and female students in cooperative learning, but when faced with gender prejudice in school education, teachers from Norway pay more attention to reducing gender gaps compared with Chinese teachers.
\end{abstract}

Keywords: Gender equality, Children education, education policy, classroom.

\section{INTRODUCTION}

Gender equality is committed to improving the situation in which the social system assigns different roles and status to individuals according to gender. It also means the universal equality irrespective of gender, sex, or sexuality [1]. Gender equality is supported by the international community, and a series of actions have been carried out, such as the Convention on the Elimination of All Forms of Discrimination Against Women issued in 1979 and The United Nations Entity for Gender Equality and the Empowerment of Women (UN Women) established in 2010. However, it is worth noting that Nussbaum pointed out that official commitments did not mean that people truly enjoy the freedom of the opportunity created by the combination of personal abilities and politics, society, and economy [2]. Therefore, gender equality not only exists in the policies and laws of various regions, but is also deeply hidden in specific life scenarios, such as homes, schools, and workplaces.

As mentioned above, gender equality is embodied in various specific fields, and education is one of the important ones. Gender equality or inequality is likely to be learned by young people in the education system. Bourdieu's cultural capital theory provides a theoretical basis for the above hypothesis. This theory explains how an advantage is hereditary within the class. Bourdieu believes that education is a manifestation of the cultural capital [3], and a process of standardized transformation of economic capital into cultural capital. This cultural capital will eventually become economic capital, thus completing the inheritance of the capital. In the patriarchal society with a long history, men as a group with preferential treatment can be regarded as a class inherited with cultural capital. Therefore, in the topic of gender equality, it is significant to investigate whether the education maintains the patriarchal society's oppression of disadvantaged groups or promotes gender 
equality and reduces discrimination. For instance, the viewpoints presented in the textbooks position women as auxiliary roles in family life and men as important roles in public life, which legitimize women's disadvantaged position and strengthens the inequality between the genders [4].

Children's education is a critical period for gender shaping. The psychological environment and physical conditions of Children determine their high plasticity [5]. Classroom is an important part of school education and it is the main place for children to interact with teachers and peer groups. In classroom, teachers and peer groups directly pass on social and cultural experiences to children, especially for teachers, since they have the rights to directly interfere with children's education. Vygotsky thinks that the random psychological mechanism of people is not innate or inherent, but develops in the process of interacting with the surrounding environment and other people. For children, this means their initial subjective knowledge of the world can only become objective knowledge through social acceptance [6]. Holland and Lachicotte believes that cultural products, tools, and labels are all creating children's identities for themselves and others [7]. This is the process of cultural inheritance. Children use the acquired definitions and conclusions to concretize their ambiguous identities. However, the above-mentioned marks may allow children to inherit existing prejudices and discrimination. For example, teachers claim that girls are not good at math and physics during instruction, which will undoubtedly have a negative impact on children's identity perception. Therefore, in the interaction process between teachers, peer groups, and children in the classroom, the underlying gender equality (or inequality) will be learned by children. Gender equality is reflected in the situation in the classroom, such as the attitude of teachers and pedagogy, and the way of cooperation between children.

According to the Global Gender Gap Report 2020 from the World Economic Forum, Nordic countries at a high level in gender equality, for example, this report claims that Iceland, Norway, and Finland are the three countries which are closest to gender equality in the world [8]. In addition, a series of studies that focus on gender equality in education use Norway as a model in this field [9-11]. Therefore, gender equality in children education in Norway will be one of the research objects of this study. In contrast to Norway, China is accused of insufficient efforts in gender equality. For example, in the above report, China is ranked $106^{\text {th }}$ [8]. Therefore, it is valuable to compare the gender equality in children education between these two countries.

In previous research, the challenges faced by Norway and China in gender equality education are similar, the harm of stereotypes to gender equality is still obvious [12,13]. Moreover, Sex education in China and Norway are similar in pedagogy, and both adopt integrated teaching methods to help children understand gender equality $[14,15]$. However, the weaknesses of past research are discovered in the process of literature review. Firstly, the research on gender equality in Norway is not specific enough. Few studies focus solely on the situation in Norway. On the contrary, a series of studies put Norway in the context of Europe or Nordic countries [12,15,16]. Secondly, in China, in the empirical research on sex education and gender equality in education, most of the samples studied are from universities, urban areas, and economically developed provinces, while rural and underdeveloped areas are ignored $[14,17,18]$. Finally, in past studies, gender equality in children's classrooms in China and Norway has rarely been mentioned.

The purpose of this research is to find out the differences and gaps between the gender equality in children's education in Norway and China. In order to achieve this purpose, two specific research questions are raised. Firstly, when comparing the educational policies in Norway and China, what differences can be found about children's gender equality education? Secondly, when comparing classroom situation in Norway and China, what differences can be found about children's gender equality education? Therefore, this paper is divided into two parts. First, the paper will discuss the policies for children's gender equality education in Norway and China, as well as demonstrates the differences and similarities between educational policies in Norway and China. Second, the paper will analyze the gender equality situation in children's classrooms in Norway and China to compare the differences and similarities between gender equality situation in children's classrooms in Norway and China.

\section{RESEARCH DESIGN AND METHODOLOGY}

\subsection{Research Design}

In the comparative study of gender equality in Chinese and Norwegian class situation, the research process will use quantitative research when investigating the gender equality situation in Chinese classroom. Related questions about the gender equality situation in students' classrooms are designed in the questionnaire. By distributing questionnaires at random and using quantitative research to analyze the data of the collected questionnaires, the characteristics of gender equality situation in Chinese class can be analyzed and compared with those in Norwegian class. In the process of data analysis, wjx.cn will be used. 


\subsection{Data Collecting Methods}

\subsubsection{Document analysis}

By reading and analyzing relevant policy documents and laws, relevant policies on gender equality in children's education in Norway and China can be found for comparison of similarities and differences.

Due to the limitation of geographical location, it is difficult to conduct questionnaire distribution when studying the children's classroom situation in Norway. Therefore, relevant data can be collected through literature research under current research conditions. Through literature research and analysis, data about gender equality in Norway's class can be collected. For example, the general ratio of boys to girls in Norway's classrooms can be found in the literature.

\subsubsection{Questionnaire}

When studying the classroom situation of children's education in China, data are collected by sending questionnaires. In the process of data collection, in order to ensure objectivity, questionnaires are distributed at random. Survey questions are carefully designed in order to get as much information about gender equality in Chinese children's classes as possible. For example, in the questionnaire, questions are asked like: In your primary school classes, Are boys or girls asked more often by the teachers?

\subsection{Ethical Consideration}

During the process of questionnaire collection, the personal information of respondents will be kept confidential and will not be disclosed intentionally. Personal information will not be used for purposes other than research.

\subsection{Limitation}

When studying the children's classroom situation in gender equality in China, about 100 questionnaires are handed out and collected. However, in the study on the classroom situation in Norway, due to the limitation of geographical location, all the team members in the research group are in China. Therefore, data cannot be collected by issuing questionnaires in Norway. The limited data about children's classroom situation in gender equality in Norway collected only through literature research and online research may affect the comparability of the research.

Moreover, due to the geographical limitation, most of the questionnaires were distributed in Liaoning Province and Beijing. The situation in these two regions in China may be different from that in the rest of China.

\section{RESULT}

\subsection{Gender equality policy in Norwegian children's education}

In this section, the Norwegian government's efforts on gender equality in education will be listed, which includes policies issued by the government and specific measures taken nationwide. In order to promote gender equality in education, the Norwegian government has issued a series of policies to ensure the elimination of discrimination and injustice in education, such as the Ministry of Education and Research's 2008-2010 action plan to achieve gender equality in kindergartens and basic education in 2008. It is worth noting that Norway's specific anti-discrimination policies in the field of basic education are not rich. This may because that they already have a series of cross-disciplinary anti-discrimination policies, such as the Gender Equality Act or the 2010 Gender Equality Action plan [19]. In addition to issuing policies or laws, the Norwegian government has also taken a series of other actions to promote gender equality in education. For example, the project of ENT3R, in this project, higher education students provide homework support for secondary education students, and act as role models and mentors. ENT3R is a national program that is completely free for secondary education students [20]. Norway's ENT3R project challenged gender prejudice. They recruited more women and encouraged women to join traditionally male-dominated courses such as medicine, economics, and management [19]. Moreover, the Ministry of Education and Research is committed to preventing sexual harassment and bullying and is committed to creating a reasonable and fair learning environment. They have compiled a guidebook on gender equality in teaching in elementary and junior high schools, named Undervisning om seksualitet. Et ressurshefte for larere $i$ grunnopplaringen, which proposes methods and strategies to promote gender equality in daily classroom work [19]. In summary, given that there are already national gender equality and anti-discrimination laws, the Norwegian government has not proposed excessive laws and policies in the education field, but rich educational programs and specialized guidance have been found in this field.

\subsection{Gender equality policy in Chinese children's education}

\subsubsection{China guarantees women's status}

In September 1995, the fourth World Conference on Women held in Beijing, China took gender equality as a basic national policy for the first time. In the white paper on China's gender equality and women's development, it was pointed out that China implemented 
a special support policy for girls to ensure equal access to compulsory education for school-age girls. The average length of schooling of Chinese women has increased and the gender gap has narrowed [21]. According to the sixth national population census of China, in 2010, the average number of years of education for women over 6 years old reached 8.4 years, 1.3 years higher than 10 years ago, and the gap with men was 0.2 years smaller than 10 years ago [22]. In 2019, China will formulate Several Provisions on the Prohibition of hindering the implementation of compulsory education to protect the right of school-age children and adolescents to receive compulsory education. It is forbidden to carry out full-time education and training in the name of "traditional culture" and "women's morality" education, instead of compulsory education in schools [23]. It is necessary to hold accountability in strict accordance with laws and regulations to ensure that school-age children and adolescents receive compulsory education.

\subsubsection{China adjusts the gender ratio of teachers}

The Chinese government has announced a series of measures to balance the number of male and female teachers. This is mainly achieved by cultivating more male teachers. For instance, since 2010, Jiangsu Province has recruited 300 male kindergarten normal students free of charge every year. It wants to achieve the goal of having more than one male teacher in each kindergarten in Jiangsu in three to five years [24]. Guangxi Province implemented the two-year preschool education free normal male orientation training plan in 2013, recruiting and training 100 male preschool teachers free of charge every year [25]. The same measures can also be found in Fujian and Hunan provinces [26,27].

\subsubsection{China advocates gender friendliness}

The Chinese government is committed to reducing gender discrimination and bullying. In China, the content of gender equality has been added to teacher training programs and normal university courses to strengthen the social gender awareness of education administrators [28]. In addition, sexual violence and sexual harassment on campus are concerned, especially female students and sexual minorities [29]. School psychological counseling has attracted attention, and the Ministry of Education has issued the Guidelines for the Construction of Psychological Counseling Rooms in Primary and Secondary Schools to help solve psychological problems such as gender discrimination among primary and secondary school students [29].

\subsection{The situation of gender equality in the classroom of Norwegian children}

Norway values gender equality in education. Firstly, the enrollment of the gender of students is balanced [30]. This reflects equal educational opportunities. In addition, teachers in Norway are committed to solving the issue of stereotypes in the classroom. For example, girls are encouraged to play boys' games. Children's activities are not restricted by gender. In kindergarten, boys can play with dolls and girls can play with mud. No teacher will label children with gender. From the perspective of traditional gender concepts, "playhouse" is more attractive to girls, but the current gender role model has changed, boys have begun to play the role in "playhouse" which cooking and taking care of children [31]. boys in Norwegian primary schools can be more emotional and kind-hearted. They can also talk about their feelings and their stories. Boys can also hold other hands. Physical contact between boys is no longer defined as feminization [32]. However, Wu points out that the number of primary and secondary school teachers in Norway has increased by 12400 in the past eight years [33], of which only 400 are male teachers. This has reduced the proportion of male teachers in primary and secondary schools to $30 \%$. In summary, from the beginning of kindergarten education, Norway has emphasized that educational activities should be based on gender equality. Huo believes that the duty of Norwegian teachers is to change the traditional gender role model [31]. Kindergartens will not reinforce children's traditional gender identity. They also provide teaching materials and activities that are not restricted by gender.

\subsection{The situation of gender equality in the classroom of Chinese children}

In order to understand the situation of gender equality in Chinese children's classrooms, this study adopted a questionnaire survey. 350 questionnaires were retrieved, of which 342 were valid questionnaires. According to the results of the questionnaire, there were 182 male respondents and 160 female respondents.

The questionnaire survey revealed a series of the current status of gender equality in Chinese children's education. Firstly, according to Question 2, the ratio of boys to girls in Chinese elementary school classes is revealed. Of the 342 respondents, $34.5 \%$ choose nearly $1: 1,30.99 \%$ choose $6: 4$, and few others choose other ratios. According to the results of the questionnaire, the proportion of male and female students in primary schools in China is relatively balanced, and in some classes, the number of male students is slightly higher than that of female students. 
Table1. Ratio of male to female students in elementary school classes in China

\begin{tabular}{ccc}
\hline Options & Subtotal & Proportion \\
\hline $1: 1$ & 118 & 0.3450 \\
$6: 4$ & 106 & 0.3099 \\
$7: 3$ & 53 & 0.1550 \\
Less than $1: 1$ & 45 & 0.1316 \\
More than $7: 3$ & 20 & 0.0585 \\
\hline
\end{tabular}

In the questionnaire, a series of questions reflect the potential impact of gender stereotypes on students' curriculum preferences. For example, the third and fourth questions asked boys' and girls' respective levels of participation in stereotyped male-dominated classrooms. The third and fourth questions asked boys and girls how much they participated in stereotypical male-dominated classes (football class and basketball class). In the study of these two questions, the questionnaires answered by male students are put together and those answered by female students are put together to compare the data. Among the male interviewees, $43.41 \%$ had attended football lessons in primary school or played football in physical education class. Among female respondents, only $29.38 \%$ had taken football lessons in primary school or played football in physical education. The data shows that there is still a significant difference between boys and girls in their participation level in the stereotyped male-dominated football class, and this difference also shows up in the basketball class. In the fifth question, respondents are asked to rank six subjects according to how much they liked them. Among male respondents, according to the results of data analysis, the most popular courses for them are physical education and computer science. Among female respondents, the most popular courses for them are art and music.

Table 2. Subjects preferred by Chinese elementary school students

\begin{tabular}{ccc}
\hline Options & \multicolumn{2}{c}{ Average score } \\
\hline & Male & Female \\
Computer & 3.85 & 3.21 \\
PE & 3.98 & 3.55 \\
Music & 3.20 & 3.64 \\
Art & 3.78 & 4.23 \\
Math & 2.57 & 2.68 \\
English & 3.07 & 3.35 \\
\hline
\end{tabular}

In the sixth question, when asked whether there are more male or female administrators in primary schools, according to the results of 342 survey results, $54.97 \%$ of respondents choose the answer of "more male" and $45.03 \%$ choose the answer of "more female". In the seventh question, according to the survey result, $42.4 \%$ of respondents have more male teachers in primary school classrooms, and $57.6 \%$ of respondents have more female teachers in primary school classrooms.
Table 3. Gender ratio of administrators and teachers in elementary schools in China

\begin{tabular}{ccc}
\hline Options & \multicolumn{2}{c}{ Proportion } \\
\hline Male & Administrators & Teachers \\
Female & 0.5497 & 0.4240 \\
Moreover, for & 0.4503 & 0.5760 \\
\hline
\end{tabular}
questionnaire is based on the statistics of the number of times that boys and girls answer questions in primary schools in China. According to the results of questionnaires, girls answer questions more often and are asked questions more often than boys. In question 11 , when asked whether primary school teachers tend to divide students of the same gender into a group, according to the results of questionnaires, nearly half of the students choose to be agreed, and only $26.03 \%$ disagreed.

\section{DISCUSSION}

According to the results of the research, education policies in Norway and China require schools to help students establish a gender equality perspective. These policies also work to reduce gender discrimination, bullying, and sexual harassment of children in school life. However, in the policies of the two countries, a series of significant differences were found. Firstly, as one of the important ways for children to acquire the concept of gender equality, sex education is placed at a crucial position in Norwegian education policy. On the contrary, it is difficult to retrieve specific sex education policies and official teaching materials on the official website of the Chinese education department. In China, mixed research conducted by UNESCO and UNFPA on school sex education in 30 schools in 6 provinces confirms this conclusion. The research shows that the Chinese government has no clear requirements for sex education courses, nor does it provide textbooks and teacher training [14]. Second, the influence of peer groups is emphasized in Norwegian education policy. Peer groups may be an overlooked source of children's gender equality education. Strange believes that the participation of peers enhances children's confidence in discussing gender topics [34]. Walker also pointed out that the informality brought about by peer groups is beneficial, for example, they can discuss more openly, which will make the child feel relaxed [35]. Unfortunately, the role of peer groups has not been paid attention to by China's education policy. Gender equality education in China is still led by teachers. Finally, it is controversial that China is committed to balancing the ratio of male and female teachers in children's education. Guo pointed out that the gender structure of Chinese teachers is imbalanced, with female teachers making up most kindergartens, primary and secondary schools [36]. Obviously, the Chinese government believes that the gender ratio of male and female teachers is closely related to children's 
awareness of gender equality, but whether this is the case requires further verification, and this will also be a part of future studies. It is also worth noting that the reason why the gender ratio of male and female teachers is not mentioned in Norwegian policy is unknown. This may be because Norway does not have the issue of gender imbalance among teachers, or it is not considered by the Norwegian government to be related to children's gender equality education.

When comparing the classroom situation of children in China and Norway, many similarities, and differences in gender equality education can be found in the two countries. First, according to the classroom situation, both Norway and China show equality between boys and girls in terms of opportunities for education. Enrollment rates for boys and girls in Norwegian classrooms are basically the same. In China, the results of a questionnaire survey show that in most elementary school classes, the ratio of boys to girls is close to $1: 1$. Another similarity between the situation of children's classrooms in Norway and China is that teachers in both countries are committed to facilitating communication between male and female students. For example, in Norway, teachers tend to put students of different genders in the same group so that students of different genders have more opportunities to communicate. These exchanges can help reduce gender prejudice and discrimination [37]. In children's education in China, it can be seen from the survey results that teachers also tend to attach importance to gender diversity in cooperative learning. In addition, as mentioned above, both Norwegian and Chinese children's education faces the challenge of stereotypes [12,13]. However, according to the results of the research, the efforts to deal with stereotypes in Norwegian classrooms are more significant. For example, research results show that in Norwegian kindergartens and elementary schools, boys and girls have similar levels of participation in football lessons. Boys are also encouraged to play with dolls, girls can also play in the mud, and boys are also taught to be considerate, kind, and sensual. But in China, questionnaire surveys show that although most of the football and basketball activities in school physical education are open to both boys and girls, most girls prefer subjects that are stereotyped as "female's choice", such as art and music classes.

In summary, the education departments and schools in Norway and China are committed to improving gender equality in children's education and helping children establish a concept of gender equality. But it is obvious that Norway's results are more optimistic, especially in children's sex education and attention to peer groups. In addition, it needs to be clarified that although this research cannot determine the extent to which the classroom situation is affected by the policy. based on the research results, it is certain that the policies of both countries are working to solve the problems presented in the classroom situation.

This study has a series of limitations. Firstly, in the survey on gender equality in the classroom situation in China, as mentioned above, most samples come from urban areas. Although it is convenient to collect data in cities, more than half of China's population lives in rural areas, so this study may not reflect the gender equality in rural education in China [38]. Second, although in the above, the researchers tried to link official education policies and measures with gender equality in the classroom, this research cannot directly prove whether the government's efforts have affected or improved gender equality in the classroom. Furthermore, some of the research materials used in this study, especially the content of Norwegian education policy, are related reports from the United Nations. The authenticity and academic value of these reports need to be critically considered because they may be affected by political factors. Moreover, this research focused on gender equality between men and women in education, and LGBT groups were not included in the research. In future research, researchers will work to expand the sample size and diversity. In addition, as mentioned above, the potential impact of the ratio of male and female teachers in schools on children's awareness of gender equality will be further analyzed and discussed.

This research has brought a series of enlightenment to children's gender equality education, especially the issue of gender stereotypes in children's education. Despite the efforts of both countries, the stereotypes problem still exists. Brekus' unmarked theory may provide a valuable perspective. Brekus believes that the marking process may exaggerate the uniqueness of the group identity, because the unmarked group is usually larger, which implies that the characteristics of the unmarked group are generally accepted by the public [39]. For example, on the topic of gender equality, the policies and teachers are disproportionately focused on the disadvantaged position of female students, and their attention to homosexuality far exceeds that of heterosexuality. He believes that although people expect to use these asymmetric marks to eliminate prejudice, in fact, this behavior inadvertently strengthens people's stereotypes of the marked group. Therefore, he proposed a strategy of reverse marking, marking the majority, default, and unmarked groups. For example, in children's gender equality education, not only girls, but also the stereotypes and bullying faced by boys should be mentioned. In future policies and teaching, the above-mentioned methods may be worthy of the attention of education practitioners in both countries.

\section{CONCLUSION}

In conclusion, this research answers the research questions and achieves the research purpose. This study 
uses a quantitative research method to observe and compare the differences in gender equality between Norwegian and Chinese children's education. In policy, both countries have gender equality programs dedicated to reducing discrimination and bullying. The difference is that China pays more attention to the balance of male and female teachers, while Norway has higher achievements in gender equality in pedagogy and sex education. In terms of classroom conditions, teachers in both countries encourage the communication and interaction between male and female students in cooperative learning. However, when faced with gender prejudice in school education, teachers from Norway pay more attention to reducing gender gaps compared with Chinese teachers.

\section{APPENDIX}

Questionnaire on Gender Equality in Primary School Classroom

This questionnaire is to understand the gender equality situation in Chinese children's education. There are eleven questions in total. There is no right or wrong answer. Please fill it out according to your own feelings. The questionnaire is anonymous, your answers will be kept confidential, and you have the right to withdraw from the study at any time.

1. Whar is your gender?

$$
\text { a. Male b. Female }
$$

2. What's the ratio of boys to girls in your class in your primary school?
a. $1: 1$
b. $6: 4$
c. $7: 3$
$\begin{array}{ll}\text { d. }<1: 1 & \text { e. }>7: 3\end{array}$

3. Have you ever had football lessons in primary school or have you ever played football in PE class?

a. YES b. NO

4. Have you taken basketball lessons in primary school or have you ever played basketball in PE class?

a. YES b. NO

5. Rank the courses you have taken in elementary school according to your preference?

a. Computer b. PE c. Music d. Art e. Math f. English

6. Are there more men or women in the administrative staff of your primary school?

a. Male b. Female

7. Are there more male or female teachers in your primary school?

a. Male b. Female

8. In your primary school math class, do boys answer more questions or girls answer more questions? a. Boys b. Girls

9. In your primary school classroom, are teachers more likely to ask boys or girls?

a. Boys b. Girls

10. In your primary school class, when faced with difficult problems, do teachers ask boys more often or girls?

a. Boys b. Girls

11. In your primary school classroom, in cooperative learning, teachers tended to group students of the same gender

a. Strongly agree b. Agree c. Uncertain d. Disagree e. Strongly disagree

\section{REFERENCES}

[1] Gender equality. In Encyclopadia Britannica. 2021. Retrieved from https://academic-eb-com.ezproxy.lib.gla.ac.uk/level s/collegiate/article/gender-equality/600925\#articlecontributors

[2] Nussbaum, M. C. Creating capabilities: The human development approach and its implementation. Hypatia, 2009,24(3), 211-215. DOI:https://doi.org/10.1111/j.1527-2001.2009.0105 $\underline{\text { 3.X }}$

[3] Bourdieu, P., \& Richardson, J. G. The forms of capital. 1986

[4] Pan, T, Sun, Q, \&amp; Hu, Q. Research on gender inequality in junior high school mathematics textbooks. 2018. Retrieved March 09, 2021, from https://xueshu.baidu.com/usercenter/paper/show?pa perid=1g7m0030bf630t405q5h0r20yn452365\&am p;site $=x u e s h u \_s e$

[5] Wang, S, \&amp; Guo, M. (n.d.). The development of children's gender roles and its influencing factors. 2008. Retrieved March 09, 2021, from https://wenku.baidu.com/view/35389dd4312b3169 a551a47f.html

[6] Gauvain, M., \& Cole, M. (Eds.). Readings on the development of children. Macmillan.2005.

[7] Holland, D., \& Lachicotte, W. Vygotsky, Mead, and the new sociocultural studies of identity.2007.

[8] Global Gender Gap Report 2020. 2021. Retrieved 9 March 2021, from https://www.weforum.org/reports/gender-gap-2020 -report-100-years-pay-equality

[9] Cuibin Zhou, On legislative problems \& ways out for modem China women's rights and interests protection, Primary and secondary education in 
foreign countries, 2009,pp.136-138.

[10] Ondy Mo, Gender equality education in Norway,2010 (9),pp. 37-40.

[11] Wang Yifang (2017), The status and inspiration of Norwegian kindergarten teacher's learning and development, (12), 43-52

[12] Imdorf, C., Hegna, K., Eberhard, V., \& Doray, P. Educational Systems and Gender Segregation in Education: A Three-Country Comparison of Germany, Norway and Canada. In Gender segregation in vocational education. Emerald Group Publishing Limited.2015.

[13] Shao Z, \& Pang G. Retrospect and Prospect of Research on Gender Differences in College Entrance Examination. Journal of East China Normal University (Educational Sciences), 2016, 34(1), pp. 69.

[14] Field, S., \& Guez, A. The implementation of sex education in junior middle schools in China. UNESCO Publishing.2018.

[15] Parker, R., Wellings, K., \& Lazarus, J. V. Sexuality education in Europe: An overview of current policies. Sex Education,2009, 9(3), pp. 227-242.

[16] Campbell, M. The challenges of girls' right to education: Let's talk about human rights-based sex education. The International Journal of Human Rights, 2016, 20(8), pp.1219-1243. DOI: https://doi.org/10.1080/13642987.2016.1207627

[17] Gao, Y., Lu, Z. Z., Shi, R., Sun, X. Y., \& Cai, Y. AIDS and sex education for young people in China. Reproduction, Fertility and Development, 2001, 13(8), pp.729-737.

[18] Wang, B., Hertog, S., Meier, A., Lou, C., \& Gao, E. The potential of comprehensive sex education in China: findings from suburban Shanghai. International Family Planning Perspectives, 2005, pp. 63-72.

[19] UN Committee on the Elimination of Discrimination Against Women (CEDAW), Consideration of reports submitted by States parties under article 18 of the Convention, Ninth periodic report of States parties due in 2016: Norway, 1 June 2016, CEDAW/C/NOR/9, available at: https://www.refworld.org/docid/ 582d7ead4.html [accessed 9 March 2021]

[20] EU STEM COALITION. 2020. COVID-19 series: Norway - ENT3R homework support programme. [online] Available at: <https://www.stemcoalition.eu/publications/covid19-series-norway-ent3r-homework-support-progra mme> [Accessed 9 March 2021].

[21] Information Office of the State Council of the people's Republic of China, White paper on gender equality and women's development in China,2015.

[22] National Bureau of statistics of the people's Republic of China, Report on the sixth national census of China,2010.

[23] General Office of the Ministry of Education, Some provisions on Prohibition of hindering the implementation of compulsory education,2019.

[24] Department of education of Jiangsu Province, Notice on the pilot work of free education for normal students, 2010.

[25] Department of education of Guangxi Zhuang Autonomous Region, Inside and outside the classroom: teaching and Research Forum, (000)006, 2013.

[26] Department of education of Fujian Province, Key points of work in 2014, 2014.

[27] Department of education of Hunan Province, Special plan for public funded directional training of teachers in rural primary schools and kindergartens, 2016.

[28] Ministry of Education of the People's Republic of China, Reply of the Ministry of education to recommendation No. 5232 of the fourth session of the 12th National People's Congress, 2016.

[29] Ministry of Education of the People's Republic of China, Reply of the Ministry of education to recommendation No. 7727 of the fifth session of the 12th National People's Congress, 2017.

[30] Webster, C. 2021. Retrieved 9 March 2021, from https://hvlopen.brage.unit.no/hvlopen-xmlui/bitstre am/handle/11250/2393677/Chisoko_Siankata.pdf?s equence $=1 \&$ is Allowed $=y$

[31] Huo, L. 2021. Retrieved 11 March 2021, from https://kns.cnki.net/kcms/detail/detail.aspx?dbcode $=$ CJFD\&dbname $=$ CJFDLAST2020\&filename $=$ HSJ $\underline{Y 202006014 \& v=m 6 D i T D D P F 7 \% 25}$

[32] Gender equality creates new school boys, Norwegian research shows. 2021. Retrieved 9 March 2021, from https://www.sciencedaily.com/releases/2013/09/13 $\underline{0919085712 . h t m}$

[33] Wu, P. 2021. Retrieved 9 March 2021, from http://news.eastday.com/epublish/gb/paper148/200 $\underline{\text { 10812/class014800014/hwz460 }}$

[34] Strange, V. \& RIPPLE Study Team. Randomized Intervention of PuPil-Led sex Education, Peer-led 
sex education characteristics of peer educators and their perceptions of the impact on them of participation in a peer education programme, Health education research, 2002, vol. 17, no. 3, pp. 327-338.

[35] Walker, J. Parents and sex education-looking beyond 'the birds and the bees'. Sex Education. 2004, pp. 239-254.

[36] Guo, J. Teacher gender socialization and professional development from the perspective of gender, Master's thesis, Yunnan Normal University, 2013.

[37] Byrd \& Zhang. Perceptions of Interability Communication in an Interpersonal Relationship and the Reduction of Intergroup Prejudice. Western Journal of Communication (1), 2020. DOI:10.1080/10570314.2019.1636131.

[38] National Bureau of Statistics. Tabulation on the 2010 population census of the people's republic of China. Beijing. 2010.

[39] Brekhus, W. A sociology of the unmarked: Redirecting our focus. Sociological Theory, 1998,16(1), 34-51. 